\title{
Validating a Problem-Based Learning Process Assessment Tool in a Nepalese Medical School
}

\author{
Upadhyay, S.K. ${ }^{1}$, Bhandary, S. ${ }^{1}$, Ghimire, S.R. ${ }^{2}$, Maharjan, B.R. ${ }^{3}$, Shrestha, $I .{ }^{4}$, Joshi, M. ${ }^{5}$, \\ Vaidhya, $S{ }^{6}$
}

\begin{abstract}
Introduction: The newly established Patan Academy of Health Sciences (PAHS) has incorporated measurement of non-cognitive skills and behaviours into the summative assessment in the setting of problem based learning (PBL). This study aims to validate a PBL process assessment tool for PAHS.
\end{abstract}

Methods: A list of 72 items of student behaviours observable in PBL tutorials was compiled from literature review. They were categorized under ten broad dimensions consistent with predefined PAHS Graduate Attributes. A series of PBL project committee meetings and expert inputs refined the list of 72 items to 47 and categorized them under eight dimensions. These 47 items, each with a 4-point rating scale, formed the Tutor Assessment of Student Tool (TAS-Tool). Twenty-four trained faculty members used the TAS-Tool to evaluate the performance of 41 senior high school students in PBL tutorials.

Results: The internal-consistency of the TAS-Tool was very high (Cronbach's $\alpha=0.954$ ). Removal of two inconsistent items further increased it to 0.975 . Principal components analysis with varimax rotation applied to the remaining 45 items gave seven components and explained $69.47 \%$ of the variation between the components. These seven components (\% variation) were: Immersed in the Tutorial Process (20.16\%); Professional (12.71\%); Communicator and Team Leader (11.25\%); Critical Thinker (8.77\%); Reflector (6.22\%); Creative (5.95\%), and Sensitive (4.41\%).

Conclusion: TAS-Tool was found to be a reliable and valid instrument and applicable in formative PBL process assessment at PAHS starting with the pioneer cohort of medical students. Further validation of TAS-Tool through longitudinal study with PAHS students is required for summative purpose.

Key words: Problem Based Learning, Summative Assessment, Tool Validation, Factor Analysis, Nepal

\section{Introduction}

Patan Academy of Health Sciences (PAHS), a newly established health science university in Nepal, has adopted problem-based learning (PBL) as the principal pedagogic strategy for fostering important generic skills (non-cognitive behaviours).

\footnotetext{
${ }^{1}$ Department of Community Medicine

${ }^{2}$ Department of Anatomy

${ }^{3}$ Department of Biochemistry

${ }^{4}$ Department of Physiology

${ }^{5}$ Department of Pharmacology

${ }^{6}$ Department of Pathology

School of Medicine, Patan Academy of Health Sciences, Nepal.

Corresponding Author:

Dr. Shambu Kumar Upadhyay, Associate Professor, Department of Community Health Sciences, School of Medicine, Patan Academy of Health Sciences (PAHS), Lagankhel, Lalitpur, G.P.O. Box: 26500, Kathmandu, Nepal

Email:shambhu.upadhyay@pahs.edu.np
}

These include self-directed learning, good communication, team leadership, and critical and reflective thinking (Wood, 2003; Schmidt et al., 2006; Tiwari et al., 2006; Koh et al., 2008). These generic skills are consistent with the predefined PAHS Graduate Attributes (Morgan, 2009). PAHS decided to incorporate their measurement into formative assessment but, most importantly, into summative assessment too in the setting of PBL (Upadhyay et al., 2011).

PBL implementation varies with the setting (Maudsley, 1999; Leung \& Wang, 2008) and $\mathrm{PBL}$ process assessment is largely confined only to formative purposes (Eva, 2001; Elizondo-Montemayor, 2004). Since no locally validated $\mathrm{PBL}$ assessment tool was available, the need for such a tool became evident for PAHS before enrolling the pioneer cohort of medical students in June 2010. 
The primary aim of this study was to develop and validate a PBL process assessment tool for evaluating non-cognitive skills and behaviours of medical students in PBL settings at PAHS.

\section{Methods}

A PBL project committee was formed and comprised of the authors who had previous experience with PBL in other medical school (Dixit \& Sharma, 2003) in Nepal. The committee conducted extensive literature review and obtained a preliminary list of 72 items of student behaviours considered observable in PBL tutorial sessions (Hebert \& Bravo, 1996; Des Marchais \& Vu, 1996; Das, 1998; Valle et al., 1999; Ladouceur et al., 2004; ElizondoMontemayor, 2004; Tan \& Tan, 2006; Papinczak et al., 2007; Leung \& Wang, 2008). The items were categorized into ten broad dimensions, namely: Preparation, Participation, Self-Directed Learning, Critical Thinking, Professionalism, Communication Skills, Group Skills, and Respect for Colleagues, Scientific Communication, and Reflectiveness. These dimensions were in line with the predefined PAHS Graduate Attributes (Morgan, 2009).

A series of the PBL project committee meetings refined the list of 72 items to 47 categorized under eight dimensions through consensus of the group. After input from one internal and two external experts, the list was finalized. These 47 items formed the Tutor Assessment of Student Tool (TAS-Tool). The individual items were evaluated using a 4-point rating scale distributed as 'Unacceptable (0)', 'Needs improvement (1)', 'Good (2)', and 'Excellent (3)'. An overall subjective rating scale distributed as 'Below expectation (0)', 'Borderline (1)', and 'Meets expectation (2)' was added on TAS-Tool.

The subjective rating scale was incorporated to calculate the pass-mark using a criterionreferenced "borderline" method along with space for open-ended comments from tutors for further research purpose. PBL tutorial sessions with higher secondary school students pursuing science courses were conducted in April 2010 to assess the relevance and usefulness of the TAS-Tool using a PBL case written for real-time use for incoming pioneer cohort of PAHS medical students. These school students were eligible applicants for undergraduate medical education in Nepal according to the Nepal Medical Council (2010).

Three PBL tutorial sessions, each of two hours duration, were conducted using a PBL case that progressively unfolded over a week with a day in between two tutorials for self-directed learning by the students. These sessions were conducted in six groups each comprising four faculty members and 7-8 students. A total of 24 faculty members trained a priori in PBL facilitation process and 45 volunteer students participated in all three tutorial sessions and a one-hour wrap-up session. A one-day orientation program on $\mathrm{PBL}$, its process, and assessment was organized separately for students as well as faculty with emphasis on evaluation of TAS-Tool a week before conducting PBL tutorial sessions. Faculty tutors were briefed on and provided with the PBL case and a tutor-guide for further reading and preparation.

Of the four faculty members in each PBL group, one faculty member in each group facilitated all three tutorial sessions while the other three faculty members silently observed the process but all four evaluated the students on completion of all three sessions (i.e. at the end of $3^{\text {rd }}$ session) using the TAS-Tool. A reflection meeting was held separately for faculty and students to share their insights/experiences about the overall PBL process, which was attended by the PAHS authorities including the founding Dean of School of Medicine.

TAS-Tool data were entered in Microsoft Excel 2007 spreadsheet and analyzed using the SPSS for Windows Version 15.0. Internalconsistency reliability of the TAS-Tool was assessed using Cronbach's alpha whereas its internal-construct structure was assessed through Principal Component Analysis (PCA) with varimax rotation to validate it at the local level. Applicability of the PCA was assessed using Kaiser-Meyer-Olkin (KMO) and Barlett's Sphericity Tests. Factor loading of 0.4 was used as the cut-off to determine the emerging dimensions on exploratory factor analysis.

Written consent was taken from the students and verbal consent was taken from faculty for their participation in the PBL tutorial sessions in this study.

\section{Results}

Using the TAS-Tool, a group of twenty four faculty members comprising of nine each from basic and clinical sciences, four from general science and two from community health science evaluated 41 out of 45 students, who participated in all three tutorials as well as the case wrap-up session. Of these 41 students, 21 were females and 20 males with the mean (SD) age $18.44(1.25)$ years and age range 16-20 years. 
Data analysis revealed the internal consistency (Cronbach's alpha) of the 47-item questionnaire. Although the TAS-Tool was planned to be validated using at least 188 samples (47 items $\times 4$-point rating scale $=188$ samples), only 162 samples could be administered due to the drop out of four students in the last tutorial session. Again, due to missing data in one or more items, the tool was validated with only 155 completed samples out of 162 administered. According to Guadagnoli \& Velicer (1988, cited in Hebert \& Bravo, 1996), this number is considered more than the minimum sample size of 100 required to ensure the relative stability of component pattern in a factorial analysis.

Nonetheless, Kaiser-Meyer-Olkin (KMO) test measuring the sampling adequacy was found as 0.938 , which is above the recommended value of 0.900 for conducting exploratory factor analysis. Similarly, Barlett's Test for Sphericity also showed the applicability of exploratory factor analysis as it was also found to be highly significant $(X 2=5798, p<0.001)$. Both these tests indicate that PCA was suitable in terms of sample size and assumption of Sphericity for the data obtained by administering the TASTool. Application of the PCA with varimax rotation revealed seven components (dimensions) from the sample $(\mathrm{N}=155)$ explaining $69.47 \%$ of variance $\left(\sigma^{2}\right)$ among the 45-items as shown in Table1 (page 22-23).

Based on the significant item-wise factor loadings in each component (i.e. 0.4 and above), the PBL project committee members were asked to come up with plausible names for these dimensions. The committee decided in consensus to name the 7 dimensions as: Immersed in Tutorial Process (Factor/Component 1), Professional (Factor/Component 2), Communicator and Team Leader (Factor/Component 3), Critical Thinker (Factor/Component 4), Reflector (Factor/Component 5), Creative (Factor/Component 6) and Sensitive (Factor/Component 7) explaining 20.16\% (15 items), $12.71 \%$ (10 items), $11.25 \%$ (10 items), $8.77 \%$ (4 items), $6.22 \%$ (3 items), 5.95\% (2 items) and $4.41 \%$ (1 item) of variance respectively.

\section{Discussion}

Adoption of PBL strategy should closely align with the assessment measures that reflect the learning process and outcomes so as to foster desired attributes in learners as well as achieve the intended educational goals. Although plenty of literature describe the assessment of process and outcomes of PBL, there is paucity of standardized/validated tools (Hebert \& Bravo, 1996; Valle et al., 1999; Leung \& Wang, 2008; Marcangelo et al., 2009). One reason for this may be, as mentioned by (Major and Palmer, 2001) and Leung and Wang (2008) that each particular PBL environment is unique and, hence, often requires a PBL assessment strategy adapted to the specific setting and intended program objectives. The development and validation of the TAS-Tool was driven by such a need of monitoring and evaluating the progress made by students in non-cognitive domain (independent of cognitive domain) in $\mathrm{PBL}$ at PAHS.

The internal consistency reliability of the 47 items TAS-Tool was found to be very high (Cronbach's alpha $=0.954)$. However, two items namely 'shows meaningful participation relevant to case discussion' and 'arrives in time and attends tutorial regularly' were found to be inconsistent i.e. negatively correlated and uniformly scored respectively. The negative correlation for the item- 'meaningful participation in the PBL tutorial process'- might have arisen due to students not giving high importance to it as it was not academically valuable to them. It could have also arisen due to tutor's variability to judge this item. Uniform scoring on item- 'arrives on time and attends tutorial regularly' (punctuality) might have been due to less strict scoring of the voluntary participation of the students by faculty tutors to allow for maximum student participation in the process. This led to the removal of these two items, which further increased the internal consistency reliability (Cronbach's alpha to 0.975) of TAS-Tool.

The internal construct structure i.e. construct validity of TAS-Tool was tested by PCA with varimax rotation. The seven dimensions obtained from PCA and identified as Immersed in Tutorial Process, Professional, Communicator and Team Leader, Critical Thinker, Reflector, Creative, and Sensitive were found closer to the previously agreed eight dimensions. This shows that TAS-Tool is able to capture more than $2 / 3^{\text {rd }}$ of the variability in the formative PBL process assessment in the local context of PAHS and is suitable for further study based on longitudinal data obtained from its application for summative purpose.

Tutor's assessment of students has been reported as being highly supportive of the learning process as well as good assessment practice in PBL settings (Rothman \& Page, 2002). 


\begin{tabular}{|c|c|c|c|c|c|c|c|}
\hline \multirow[b]{2}{*}{ Items on students' skills and behaviors in PBL } & \multicolumn{7}{|c|}{ Component } \\
\hline & 1 & 2 & 3 & 4 & 5 & 6 & 7 \\
\hline \multicolumn{8}{|l|}{ Factor 1} \\
\hline $\begin{array}{l}\text { Uses variety of authentic information resources to obtain needed } \\
\text { information }\end{array}$ & 0.812 & 0.113 & 0.139 & 0.043 & 0.163 & 0.101 & 0.076 \\
\hline Brings new information relevant to discussion & 0.800 & 0.018 & 0.271 & 0.075 & 0.088 & 0.061 & 0.176 \\
\hline $\begin{array}{l}\text { Integrates knowledge and information derived from multiple sources in } \\
\text { a meaningful way }\end{array}$ & 0.742 & 0.172 & 0.293 & 0.287 & -0.002 & 0.044 & 0.170 \\
\hline Completes all assigned tasks to the level appropriate for the task & 0.723 & 0.178 & 0.092 & 0.222 & 0.118 & 0.280 & -0.141 \\
\hline Makes clear, concise and coherent summary & 0.699 & 0.024 & 0.218 & 0.304 & -0.018 & 0.053 & 0.238 \\
\hline Shows evidence of reading diverse and recent sources about the case & 0.699 & 0.091 & 0.097 & 0.168 & 0.245 & 0.364 & -0.161 \\
\hline $\begin{array}{l}\text { Actively makes effort to enhance his/her own level of understanding } \\
\text { and competence }\end{array}$ & 0.695 & 0.140 & 0.188 & 0.201 & 0.218 & 0.220 & -0.051 \\
\hline Presents information relevant to the case clearly and concisely & 0.680 & 0.142 & 0.305 & 0.294 & 0.005 & 0.120 & 0.118 \\
\hline Supports statements logically with appropriate references & 0.637 & 0.203 & 0.116 & 0.259 & 0.052 & 0.031 & 0.307 \\
\hline Shares own knowledge and information with group & 0.577 & 0.251 & 0.422 & 0.217 & 0.076 & 0.278 & 0.152 \\
\hline Evaluates various information resources & 0.569 & 0.148 & 0.168 & 0.315 & 0.213 & 0.328 & -0.003 \\
\hline Participates in each step of problem analysis & 0.516 & 0.255 & 0.502 & 0.076 & 0.022 & 0.264 & 0.173 \\
\hline Willingly takes on assignments & 0.504 & 0.365 & 0.235 & 0.105 & 0.013 & 0.406 & 0.092 \\
\hline Contributes in developing relevant learning issues & 0.481 & 0.173 & 0.291 & 0.443 & 0.118 & 0.182 & 0.228 \\
\hline Explains concepts clearly & 0.420 & 0.193 & 0.255 & 0.352 & 0.139 & 0.360 & 0.360 \\
\hline \multicolumn{8}{|l|}{ Factor 2} \\
\hline Respect other's cultural and religious beliefs & 0.005 & 0.824 & 0.008 & 0.006 & -0.076 & 0.100 & 0.203 \\
\hline Shows respect and sensitivity to others & 0.177 & 0.711 & 0.197 & 0.203 & 0.109 & 0.039 & -0.009 \\
\hline $\begin{array}{l}\text { Allows others to express their views and respects their } \\
\text { knowledge/perspectives }\end{array}$ & 0.024 & 0.682 & 0.264 & 0.096 & 0.247 & 0.055 & 0.017 \\
\hline $\begin{array}{l}\text { Accepts constructive criticism and feedback with openness in a non- } \\
\text { defensive manner }\end{array}$ & 0.201 & 0.671 & 0.123 & 0.035 & 0.249 & 0.109 & 0.369 \\
\hline Conducts him/herself in an honest manner & 0.257 & 0.603 & 0.266 & 0.218 & 0.251 & -0.125 & 0.123 \\
\hline $\begin{array}{l}\text { Learn from feedback and criticism by accepting responsibility for } \\
\text { improving behaviors }\end{array}$ & 0.044 & 0.600 & 0.184 & 0.284 & 0.319 & 0.139 & -0.041 \\
\hline $\begin{array}{l}\text { Takes stance for his/her point/view but agrees to change if evidences } \\
\text { shows otherwise }\end{array}$ & 0.323 & 0.514 & 0.199 & 0.223 & 0.290 & 0.201 & 0.150 \\
\hline $\begin{array}{l}\text { Provides constructive criticism and feedback (reflection, ideas and } \\
\text { suggestion) }\end{array}$ & 0.264 & 0.489 & 0.232 & 0.093 & 0.226 & 0.125 & 0.434 \\
\hline Speaks clearly and respectfully & 0.189 & 0.456 & 0.293 & 0.260 & 0.291 & 0.104 & 0.412 \\
\hline Participates actively in group evaluation (self, peer, group and tutor) & 0.175 & 0.407 & 0.243 & 0.205 & 0.187 & 0.331 & -0.111 \\
\hline
\end{tabular}


Factor 3

Encourages participation of others in group discussion

Helps to resolve misunderstanding and conflicts

Helps peers to clarify ideas

Takes the lead or intervenes appropriately to foster group process and

learning

Actively contributes towards achieving group's learning goals

Supports and/or counters statement with reasoning and evidences

Makes comments that promotes better understandings of the subject by the group

Asks appropriate questions to clarify obscure points, enhance

understanding, or stimulate discussion

Seeks consensus

Listens actively as indicated by contribution to discussions, seeking

clarification from others and summarizing discussions

\section{Factor 4}

Approaches the problem in a systematic and logical manner

Discriminates important information from non-important ones

Demonstrates ability to interpret the information given in the problem in

a logical manner

Shows ability to generate explanatory hypotheses

\section{Factor 5}

Identifies areas in need of improvement

Recognizes limits of own knowledge and ability

Takes positive step towards improving his/her weaknesses

\begin{tabular}{|c|c|c|c|c|c|c|}
\hline 0.158 & 0.420 & 0.673 & 0.050 & 0.113 & 0.116 & 0.063 \\
\hline 0.258 & 0.324 & 0.618 & 0.339 & 0.006 & 0.165 & 0.122 \\
\hline 0.409 & 0.130 & 0.613 & 0.283 & 0.303 & 0.181 & 0.016 \\
\hline 0.403 & 0.174 & 0.575 & 0.231 & 0.213 & 0.339 & 0.056 \\
\hline 0.436 & 0.243 & 0.565 & 0.344 & 0.093 & 0.263 & 0.041 \\
\hline 0.365 & 0.218 & 0.554 & 0.396 & 0.210 & 0.137 & 0.006 \\
\hline 0.426 & 0.203 & 0.531 & 0.250 & 0.304 & 0.189 & 0.075 \\
\hline 0.475 & 0.204 & 0.483 & 0.124 & 0.016 & -0.242 & 0.311 \\
\hline 0.279 & 0.325 & 0.468 & 0.076 & 0.277 & 0.302 & 0.199 \\
\hline 0.314 & 0.320 & 0.402 & 0.254 & 0.219 & 0.167 & 0.371 \\
\hline 0.417 & 0.230 & 0.211 & 0.698 & -0.042 & 0.110 & 0.082 \\
\hline 0.323 & 0.286 & 0.229 & 0.690 & 0.032 & 0.202 & 0.119 \\
\hline 0.433 & 0.183 & 0.179 & 0.686 & 0.209 & 0.043 & 0.100 \\
\hline 0.330 & 0.071 & 0.350 & 0.538 & 0.282 & 0.101 & 0.265 \\
\hline 0.175 & 0.316 & 0.170 & 0.014 & 0.763 & 0.102 & 0.219 \\
\hline 0.034 & 0.397 & 0.124 & 0.129 & 0.758 & 0.043 & 0.134 \\
\hline 0.284 & 0.483 & 0.182 & 0.155 & 0.490 & 0.043 & -0.147 \\
\hline 0.379 & 0.099 & 0.292 & 0.178 & 0.131 & 0.703 & 0.183 \\
\hline 0.479 & 0.123 & 0.256 & 0.146 & 0.005 & 0.683 & 0.157 \\
\hline 0.117 & 0.294 & 0.056 & 0.414 & 0.185 & 0.191 & 0.571 \\
\hline 20.156 & 12.705 & 11.246 & 8.772 & 6.224 & 5.952 & 4.412 \\
\hline 15 & 10 & 10 & 4 & 3 & 2 & 1 \\
\hline
\end{tabular}

\section{Factor 6}

Uses diagrams, flow charts, tables etc. to facilitate communication Draws diagrams, flow charts, and tables to explain and summarize concepts

Factor 7

Responds to a nonverbal and emotional messages

\section{Variance Explained}

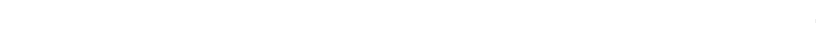


TAS-Tool is, thus, believed to enable tutors to make comprehensive evaluation of students' progress in non-cognitive domains: both formative and summative. The formative measure is expected to help students get relevant feedback and encourage them in adopting desired cognitive as well as noncognitive behaviours. However, the value of summative measure has been debated in the literatures citing the dual roles of the tutor as mentors and judge being incompatible (Blake et al., 1995). Most PBL schools have limited its use for formative purpose only (Nendaz \& Tekian, 1999; Rothman \& Page, 2002). Despite contradictory arguments, tutor ratings in PBL have been acknowledged to have positive contribution towards the composite assessment of students if reliability and validity of tools are acceptable when used summatively (Rothman \& Page, 2002).

Drop out of 4 students in the last tutorial sessions and missing data on one or more items on filled samples led to the reduction in the number of intended sample. This may be due to lack of interest and uniform adaptability to the small-group-learning environment of all students. During the reflection sessions held at the end of tutorials, students expressed that they found the PBL process very participatory and interactive whereas faculty felt they had received important hands-on experiences and gained enhanced confidence in facilitating and assessing PBL tutorials albeit tedious data completion task.

Tutor reluctance in rating the long list of items is likely to be the main limitation of the TAS-Tool as reported by other studies (Hebert \& Bravo, 1996; Eva, 2001; Ladouceur et al., 2004; Leung \& Wang, 2008) too. To address this, more work is necessary to improve the TAS-Tool with fewer and smarter items without losing its reliability and validity. Moreover, voluntary participation of students may have obscured the reflection of students' learning behaviours accurately. Hence, the generalizability of TAS-Tool in other PBL settings needs careful consideration and its further validation through a longitudinal study on PAHS medical students and with larger sample size is required.

\section{Conclusion}

Since the internal consistency reliability along with face, content and construct validity of the TAS-Tool were found to be highly acceptable, this tool is applicable in PBL settings. Therefore, TAS-Tool could add significant value to the PAHS Student Assessment System in assessing non-cognitive skills and behaviours of its students longitudinally and, thereby, foster the development of those attributes as aspired by PAHS in its graduates. Thus, it was recommended that TAS-Tool be used in PBL tutorial assessment at PAHS starting with its pioneer cohort of medical students as formative measure and to further validate it through longitudinal study before adopting it as summative measure. Most importantly, TAS-Tool may provide added value as reference to other medical schools implementing PBL in Nepal and elsewhere.

\section{Acknowledgement}

The authors would like to thank the students and teachers of Adarsha Vidhya Mandir Higher Secondary School, Lalitpur, Nepal for their cooperation and participation in the study; the founding vice chancellor of PAHS, Dr. Arjun Karki and Medical Education Unit of PAHS for their continued guidance; PAHS faculty and administration; PAHS International Advisory Board members as well as GSMC FAIMER Regional Institute faculty, fellows (2009) and staffs in Mumbai, India for their support.

\section{References}

Blake, J.M., Norman, G.R. \& Smith, E.K.M. (1995) Report card from McMaster: student evaluation at a problem-based medical school, The Lancet, 345, 8954, pp.899-902.

Das, M. (1998) Self and tutor evaluations in problembased learning tutorials: is there a relationship? Medical Education, 32, 4, pp.411-418.

Des Marchais, J.E. \& Vu, N.V. (1996) Developing and evaluating the student assessment system in the preclinical problem-based curriculum at Sherbrooke, Academic Medicine, 71, 3, pp.274-283.

Dixit, H. \& Sharma, S.C. (2003) The MBBS Programme in Nepal, Journal of the Nepal Medical Association, 41,142, pp. 341-355.

Elizondo-Montemayor, L.L. (2004) Formative and summative assessment of the problem-based learning tutorial session using a criterion-referenced system, Journal of the International Association of Medical Science Educators, 14, 1, pp. 8-14.

Eva, K.W. (2001) Assessing tutorial-based assessment, Advances in Health Sciences Education, 6, 3, pp. 243-257.

Hebert, R. \& Bravo, G. (1996) Development and validation of an evaluation instrument for medical students in tutorials, Academic Medicine, 71, 5, pp. 488-494.

Koh, G.C. H., Khoo, H.E., Wong, M.L. \& Koh, D. (2008) The effects of problem-based learning during medical school on physician competency: a systematic review, Canadian Medical Association Journal, 178, 1, pp.34-41. 
Ladouceur, M.G., Crooks, D.L. \& Schmuck, M.L. (2004) Development of an instrument to assess individual student performance in small group tutorials, Journal of Nursing Education, 43, 10, pp.447-455.

Leung, K.K. \& Wang, W.D. (2008) Validation of the Tutotest in a hybrid problem-based learning curriculum, Advances in Health Sciences Education, 13, 4, pp.469-477.

Major, C.H. \& Palmer, B. (2001) Assessing the effectiveness of problem-based learning in higher education: Lessons from the literature, Academic Exchange Quarterly, 5, 1, pp.4-9.

Marcangelo, C. Gibbon, C. \& Cage, M. (Eds.) (2009) Problem-based learning evaluation toolkit, [Online] Available at: http://www.pbldirectory. com/downloads/pbl-toolkit.pdf.

Maudsley, G. (1999) Do we all mean the same thing by" problem-based learning"? A review of the concepts and a formulation of the ground rules, Academic Medicine, 74, 2, pp.178-185.

Morgan, J.H.C. (2009) Designing an assessment tool for professional attributes of medical graduates from a new medical school in Nepal, South-East Asian Journal of Medical Education, 3, 1, pp.2-7.

Nendaz, M.R. \& Tekian, A. (1999) Assessment in problem-based learning medical schools: A literature review, Teaching and Learning in Medicine, 11, 4, pp.232-243.

Nepal Medical Council (2010) Accreditation Standards for the MBBS Degree Program, Kathmandu, Nepal: Nepal Medical Council.
Papinczak, T., Young, L., Groves, M. \& Haynes, M. (2007) An analysis of peer, self, and tutor assessment in problem-based learning tutorials, Medical Teacher, 29, 5, pp. e122-e132.

Rothman, A. \& Page, G. (2002) Problem-based learning. In: Norman GR, Van der Vleuten CPM, Newble D.I. (Eds.) International Handbook of Research in Medical Education, Great Britain: Dordrecht: Kluwer Academic Publishers.

Schmidt, H.G. Vermeulen, L. \& Van Der Molen, H.T. (2006) Longterm effects of problem-based learning: a comparison of competencies acquired by graduates of a problem-based and a conventional medical school, Medical Education, 40, 6, pp. 562567.

Tan, C.P. \& Tan, N.H. (2006) A simple instrument for the assessment of student performance in problembased learning tutorials, Annals of Academic Medicine Singapore, 35, pp. 634-641.

Tiwari, A., Lai, P., So, M. \& Yuen, K. (2006) A comparison of the effects of problem-based learning and lecturing on the development of students' critical thinking, Medical Education, 40, 6, pp.547-554.

Upadhyay, S.K., Bhandary, S. \& Ghimire, S.R. (2011) Validating a problem-based learning process assessment tool, Medical Education, 45, 11, pp. $1151-1152$.

Valle, R., Petra, L., Martínez-Gonzáez, A., RojasRamirez, J.A., Morales-Lopez, S. \& Piña-Garza, B. (1999) Assessment of student performance in problem-based learning tutorial sessions, Medical Education, 33, 11, pp. 818-822.

Wood, D.F. (2003) Problem Based learning, British Medical Journal, 326, 7384, pp. 328-330. 